\title{
Experience with Rapid Microarray-Based Diagnostic Technology and Antimicrobial Stewardship for Patients with Gram-Positive Bacteremia - CORRIGENDUM
}

In the article by Neuner, et al. ${ }^{1}$, the following citation should have been included for the Appendix on page 1366:

Adopted with permission from the Johns Hopkins Hospital Antibiotic Guidelines. Available at: www.hopkinsmedicine. org/amp. Accessed (May 12, 2014).

The authors apologize for this error.

\section{REFERENCE}

1. Neuner EA, Pallotta AM, Lam SW, et al. Experience with rapid microarray-based diagnostic technology and antimicrobial stewardship for patients with Gram-positive bacteremia. Infect Control Hosp Epidemiol 2016;37:1361-1366. 